\title{
Clustering Observations for Detecting Multiple Outliers in Regression Models
}

\author{
Han Son $\mathrm{Seo}^{1} \cdot$ Min Yoon ${ }^{2}$ \\ ${ }^{1}$ Department of Applied Statistics, Konkuk University \\ ${ }^{2}$ Department of Statistics, Pukyong National University
}

(Received March 2, 2012; Revised April 6, 2012; Accepted April 17, 2012)

\begin{abstract}
Detecting outliers in a linear regression model eventually fails when similar observations are classified differently in a sequential process. In such circumstances, identifying clusters and applying certain methods to the clustered data can prevent a failure to detect outliers and is computationally efficient due to the reduction of data. In this paper, we suggest to implement a clustering procedure for this purpose and provide examples that illustrate the suggested procedure applied to the Hadi-Simonoff (1993) method, reverse Hadi-Simonoff method, and Gentleman-Wilk (1975) method.
\end{abstract}

Keywords: Clustering, linear regression model, outliers, regression diagnostics.

\section{1. 서론}

모형추정과정에서 자료에 이상치가 포함되는 경우 여러 문제가 발생한다. 특히 모수의 추정값이 이상 치에 민감하게 영향을 받는 선형회귀모형 분석에서 이상치 탐지를 위한 다양한 방법들이 제안, 연구되 고 있다. Gentleman과 Wilk (1975)는 이상치군의 크기를 미리 추정한 후 해당되는 크기의 관찰치군들 중에서 관찰치군을 제외하고 추정된 모형의 잔차 합을 기준으로 이상치군을 선정하였다. Marasinghe (1985)은 이상치군 탐지에 요구되는 계산량을 축소하기 위해 다단계 방식으로 이상치 후보군을 구성 한 후 관찰치 각각에 대하여 이상치 여부를 검정하였다. Paul과 Fung (1991)은 이상치 후보군의 구성 을 위해 일반적 극단스튜던트화 잔차(generalized extreme studentized residual; GESR)와 영향치 정 도에 관련된 측도를 함께 고려하였다. Kianifard와 Swallow (1989, 1990)는 반복잔차(recursive resid$\mathrm{ual}$ 를 이용하여 이상치 후보군을 선정하고 후보군에 속하는 관찰치에 대하여 순차적 검정을 수행하였 다. Hadi와 Simonoff (1993)은 일정 크기의 양호 관찰치군으로부터 모형을 추정한 후 검정을 통해 이 상치군의 크기를 한 개씩 줄여가는 방법을 제안하였다. 이상치군 탐지방법에서 계산량을 축소하기 위하 여 Atkinson (1994)은 전진탐색법을 제안하였으며 Pena와 Yohai (1999)는 설명변수들이 많을 때 적용 될 수 있는 이상치군 탐지법을 제시하였다. Jajo (2005)는 제안된 여러 가지 이상치군 탐지방법에 대한 장단점을 비교하였다. 이상치군 탐지에서 이상치군의 크기를 결정하는 과정은 이상치군의 크기를 사전

This work was supported by Konkuk University (2011).

${ }^{2}$ Corresponding author: Assistant Professor, Department of Statistics, Pukyong National University, 599-1 Daeyeon 3-Dong, Nam-Gu, Busan 608-737, Korea. E-mail: myoon@pknu.ac.kr 
에 정해두거나 임의적인 판단에 의해 정해지는 것과 (Gentleman과 Wilk, 1975; Marasinghe, 1985) 이 상치군의 크기를 순차적 검정을 통해 결정하는 것 (Hadi와 Simonoff, 1993)으로 구분될 수 있으며 또 한 이상치군 크기에 따른 각 단계에서 그 이전 단계에서 탐지한 이상치군을 이용하는 방법과 각 단계별 로 독립적으로 이상치군을 탐지하는 방법으로 분류할 수 있다. 두 종류의 이상치 탐지방법에서 공통적 으로 중요하게 고려되는 점은 이상치군의 크기별로 전체 관찰치를 이상치군과 양호치군으로 나누게 되 는 과정에서 요구되는 계산량과 이상치 탐지의 정확도이다. 두 종류의 방법은 모두 각 단계별로 이상치 군을 왜곡되게 탐지할 수 있으며 특히 단계별 순차적 방법은 이전 단계에서 이상치군을 잘못 선정하였을 때 그 영향이 지속되어 결과적으로 오류를 범할 가능성이 커진다. 이와 같은 문제를 해결하기 위하여 상 대적으로 계산량에서 유리한 단계별 순차적 방법을 수행하면서 일관성이 결여되는 양호치군을 점검하는 방법이 제안되었다 (Ahn과 Seo, 2011). 본 논문에서는 인접한 관찰치가 근소한 차이로 인하여 이상치 군과 양호치군으로 상반되게 평가될 때 전체적으로 이상치군 탐지에서 가면화 효과(masking effect)나 수렁효과(swamping effect)와 같은 오류가 발생하는 경우가 많은 점을 고려하여 관찰치의 군집화를 먼 저 수행한 후 이상치군 탐지방법을 적용하는 과정을 제안한다. 가면화 효과등에 강건한 이상치 탐지법 으로 LMS를 이용한 방법 (Rousseeuw, 1984) 등이 제안되어 있지만 LMS를 적용함에 있어서 가장 큰 문제점은 과다한 계산량에 있다. 군집화를 순차적 이상치 탐지방법에 적용한다면 상대적으로 계산량이 작으면서 수렁화나 가면화로부터 자유로운 절차를 구현할 수 있다. 군집화에 의한 진단법은 영향치 분 석 등에서 제안된 바 있으며 (Gray와 Ling, 1984) 군집화에 의하여 이상치 탐지의 정확성을 높일 수 있 을 뿐만 아니라 자료의 크기가 줄어짐에 따라 계산량의 감소도 기대할 수 있다. 본 논문에서는 각 단계 별로 독립적으로 이상치군을 탐지하여 많은 계산량이 필요한 Gentleman-Wilk (1975)의 방법과 계산량 에서 유리한 순차적 방법인 Hadi-Simonoff (1993)의 방법 그리고 Hadi-Simonoff 보다 적은 계산량으로 수행할 수 있는 역 Hadi-Simonoff 방법을 제안하여 세 가지 방법에 의해 군집화 과정의 효율성을 검증 한다. 2 장에서는 본 논문에서 고려하는 세 가지 이상치 탐지법 과정을 설명하며 이 방법들을 적용하여 이상치군 탐지에 실패하게 되는 예를 제시한다. 3 장에서는 군집화 과정을 설명하고 군집화 과정을 통해 개선된 효과를 검증한다. 4장은 본 연구의 결과를 요약 정리하기로 한다.

\section{2. 이상치 탐지법}

통계분석의 대표적인 기법인 선형회귀모형 분석은 설명변수와 반응변수 간에 다음과 같은 관계식을 가 정한다.

$$
Y=\boldsymbol{X} \boldsymbol{\beta}+\varepsilon
$$

여기서 $Y$ 는 $n \times 1$ 반응변수 벡터, $\boldsymbol{\beta}$ 는 $p \times 1$ 회귀계수벡터, $\boldsymbol{X}$ 는 $p$ 개의 설명변수를 나타내는 $n \times p$ 행 렬이며 $\varepsilon$ 는 평균이 0 이고 분산행렬이 $\sigma^{2} I_{n}$ 인 $n \times 1$ 오차벡터이다.

선형회귀분석에서 다수의 이상치를 검색하기 위해 여러 가지 방법 중 본 논문에서 다루게 될 기존의 방 법은 Gentleman-Wilk (1975)의 방법과 Hadi-Simonoff (1993) 방법이며 Hadi-Simonoff (1993) 방법에 서 탐지방향을 역순으로 진행하는 역 Hadi-Simonoff 방법을 제안하여 적용한다.

세 가지 방법 중 Gentleman-Wilk의 방법은 이상치군의 크기별로 전수조사를 하므로 계산량이 가장 많 다. Gentleman-Wilk의 방법은 간략히 다음과 같이 설명될 수 있다.

1. 잠재적인 이상치의 숫자 $k$ 를 정한다.

2. 전체 데이터 $n$ 개에서 $k$ 개로 구성되는 가능한 모든 조합 ${ }_{n} C_{k}$ 에 대하여 $k$ 개의 관찰치를 제거했을 때 
발생하는 잔차 제곱합 축소치인 $Q_{k}$ 를 계산한다.

$$
Q_{k}=\sum_{i \in I_{k}} t_{i}^{2}
$$

여기서 $t_{i}=e_{i} / \sqrt{\left(1-h_{i i}\right)}, i=1, \ldots, n, e_{i}$ 는 잔차, $h_{i i}$ 는 해트행렬의 대각원소이다.

3. $Q_{k}$ 중 가장 큰 값 $Q_{k}^{*}$ 를 찾는다.

4. 만약 $Q_{k}^{*}$ 가 통계적으로 충분히 크다면 $Q_{k}^{*}$ 에 해당하는 $k$ 개 관찰치를 이상치로 판단하며 $Q_{k}^{*}$ 가 충분 히 크지 않다면 $(k-1)$ 개의 관찰치를 가지고 위의 과정을 반복한다.

일반적으로 단계 3 에서 $Q_{k}^{*}$ 를 찾는 알고리즘은 알려져 있지 않다. 또한 단계 4 에서 이상치의 크기를 결 정하는 과정에서 주로 $Q-Q$ 그림이나 $P-P$ 그림이 사용되며 주관적인 판단을 따르게 된다.

Hadi-Simonoff 방법은 기초양호군에서 시작하여 각 단계별로 이상치군의 크기를 줄여가면서 이상치 군에 대한 최종적인 이상치 여부를 순서통계량에 대한 $t$ 검정의 결과를 적용하여 결정한다. HadiSimonoff 방법의 대략적인 절차는 다음과 같다.

1. 크기 $s$ 개의 양호치군을 생성한다. 초기 양호치군의 크기 $s$ 는 $\operatorname{int}[(n+p-1) / 2]$ 이다.

2. 양호치군만으로 모형을 추정한 후 양호치군 $(M)$ 과 이상치군에 속한 관찰치에 내적 스튜던트화 잔 차(internally studentized residual) $d_{i}$ 를 계산한다.

$$
d_{i}= \begin{cases}\frac{\left(y_{i}-x_{i}^{T} \hat{\beta_{M}}\right)}{\hat{\sigma}_{M} \sqrt{1-x_{i}^{T}\left(X_{M}^{T} X_{M}\right)^{-1} x_{i}}}, & \text { if } i \in M, \\ \frac{\left(y_{i}-x_{i}^{T} \hat{\beta_{M}}\right)}{\hat{\sigma}_{M} \sqrt{1+x_{i}^{T}\left(X_{M}^{T} X_{M}\right)^{-1} x_{i}}}, & \text { if } i \notin M .\end{cases}
$$

3. $|d|_{(j)}$ 를 $\left|d_{i}\right|$ 의 오름차순으로 정리한 $j$ 번째 순서 통계량이라고 할 때 만약 $|d|_{(s+1)} \geq t_{(\alpha /\{2(s+1)\}, s-k)}$ 라고 하면 $(n-s)$ 개의 후 순위 순서통계량에 속하는 관찰치를 최종 이상치군으로 판단하며 그렇지 않을 경우 양호치군의 숫자를 한 개 늘려서 앞의 절차를 반복한다.

Hadi-Simonoff 방법과 같은 순차적인 방법은 초기 양호치의 선정이 전체 절차의 정확성에 매우 중요한 역할을 하며 이와 관련하여 Hadi와 Simonoff도 두 가지의 기초군 선정 방법을 제시하고 있다. HadiSimonoff 방법은 대략 전체 데이터의 반 정도에 해당하는 부분 데이터로부터 시작하여 순차적인 검정을 진행하므로 데이터의 크기가 크면 초기 검정 단계에서 계산량이 많다는 단점이 있다. 이를 극복하기 위 한 방안으로 Hadi-Simonoff 방법을 역방향으로 적용하여 이상치를 늘여가는 방법을 생각해 볼 수 있다. 역방향 Hadi-Simonoff 방법은 다음과 같이 정리될 수 있다.

1. 전체 자료에 의해 모형추정을 한 후 $d_{(n)}$ 에 해당하는 관찰치를 제외한 나머지 $(n-1)$ 개의 관찰치를 양호군으로 간주한 후 앞서 설명한 Hadi-Simonoff의 이상치 검정을 수행한다.

2. 이상치의 개수를 한 개씩 늘려서 Hadi-Simonoff의 이상치 검정을 반복한다. 어느 단계에서 귀무가 설이 채택되고 그 이후 일정 정도의 크기까지 검정결과가 계속 기각되면 귀무가설이 채택된 단계의 결과를 이상치군으로 판단한다.

Hadi-Simonoff와 역 Hadi-Simonoff 방법은 특정 단계에서 이상치 탐지에 오류가 발생할 경우 그 이후 단계에서도 영향을 받게 된다. 반면에 Gentleman-Wilk 방법은 이전 단계의 결과와 상관없이 이상치군 
Table 2.1. Artificial data with 7 outliers

\begin{tabular}{ccc|ccc}
\hline 번호 & $X$ & $Y$ & 번호 & $X$ & $Y$ \\
\hline 1 & -4 & 0 & 14 & 9.87 & 10.11 \\
2 & 20 & 24 & 15 & 16 & 3.03 \\
3 & 19.9 & 23.9 & 17 & 7.51 & 6.86 \\
4 & 19.8 & 23.8 & 18 & 2.67 & 2.1 \\
5 & -5 & -9 & 19 & 4.4 & 3.74 \\
6 & -4.9 & -8.9 & 20 & 7.65 & 7.57 \\
7 & -4.8 & -8.8 & 21 & 7.01 & 6.4 \\
8 & 11.36 & 11.1 & 22 & 1.28 & 1.05 \\
9 & 11.66 & 11.92 & 23 & 4.48 & 4.72 \\
10 & 0.2 & -0.27 & 24 & 4.73 & 9.39 \\
11 & 5.27 & 4.95 & 25 & 5.47 & 4.63 \\
& 10.52 & 11.38 & & & 6.04
\end{tabular}

Table 2.2. Results of applying Gentleman-Wilk method, Hadi-Simonoff method, reverse Hadi-Simonoff method for Table 2.1 data

\begin{tabular}{|c|c|c|c|c|c|}
\hline 크기 & $\mathrm{G}-\mathrm{W}$ 이상치 & Hadi-Simonoff 이상치 & 검정 & 역 Hadi-Simonoff 이상치 & 검정 \\
\hline 8 & 1891015212224 & $\begin{array}{llllllll}18 & 10 & 15 & 21 & 22 & 24 & 25\end{array}$ & $\mathrm{~N}$ & 1891015212224 & $\mathrm{~N}$ \\
\hline 7 & 18910152125 & $\begin{array}{llllll}18 & 9 & 10 & 15 & 21 & 22\end{array}$ & $\mathrm{~N}$ & 18910152125 & $\mathrm{~N}$ \\
\hline 6 & 189101521 & 189101521 & $\mathrm{~N}$ & 189101521 & $\mathrm{~N}$ \\
\hline 5 & 18101521 & 18101521 & $\mathrm{~N}$ & 18101521 & $\mathrm{~N}$ \\
\hline 4 & 181521 & 181521 & $\mathrm{~N}$ & 181521 & $\mathrm{~N}$ \\
\hline 3 & 1815 & 1815 & $\mathrm{~N}$ & 1815 & $\mathrm{~N}$ \\
\hline 2 & 18 & 18 & $\mathrm{~N}$ & 18 & $\mathrm{~N}$ \\
\hline 1 & 1 & 1 & $\mathrm{Y}$ & 1 & $\mathrm{Y}$ \\
\hline
\end{tabular}

Table 2.3. Modified Paul-Fung data

\begin{tabular}{c|cccccccccc}
\hline ID & 1 & 2 & 3 & 4 & 5 & 6 & 7 & 8 & 9 & 10 \\
\hline$X$ & 1 & 2 & 3 & 4 & 5 & 6 & -5 & -4.9 & 10 & 9.9 \\
$Y$ & 2.01 & 3.01 & 4.03 & 5.03 & 6.02 & 7.01 & -4.01 & -4 & 5.02 & 5 \\
\hline
\end{tabular}

을 탐지함으로써 이전 단계에서의 오류에 영향을 받지 않지만 이 방법도 가면화 현상 등으로 부터 자유 롭지 못하다. 다음의 예제들은 세 가지 방법들이 이상치군을 제대로 탐지하지 못하는 경우를 보여주고 있다.

예제 2.1: Table 2.1의 모의자료에서 $X_{i}$ 는 균등분포 $U(0,15)$ 에서 생성되었다. 18 개의 정상적인 $Y_{i}$ 는 $X_{i}$ 와 $\varepsilon_{i} \sim N\left(0,0.5^{2}\right)$ 에 의해 모형 $Y_{i}=X_{i}+\varepsilon_{i}, i=8, \ldots, 25$ 로 부터 생성되었고 나머지 7 개 자료 $i=1, \ldots, 7$ 는 모형에서 4 또는 6 만큼 벗어나 이상치군을 형성하도록 생성되었다. Table 2.1의 자료에 대하여 이상치 탐지방법을 실행한 결과 Table 2.2에서 보듯이 Gentleman-Wilk 방법과 Hadi-Simonoff 방법, 역 Hadi-Simonoff 방법 모두 이상치인 관찰치 1-7을 탐지하는데 실패하는 것을 알 수 있다.

예제 2.2: 두 번째 예제에서 사용하는 자료는 Paul과 Fung (1991)의 자료에서 Figure 2.1과 같이 관찰 치 9 와 10 이 이상치군을 형성하도록 수정된 자료이다 (Table 2.3). 이 자료에 대하여 세 가지 방법을 적 용하여 이상치를 탐지한 결과 Table 2.4에서 알 수 있듯이 Gentleman-Wilk 방법은 이상치의 각 단계별 


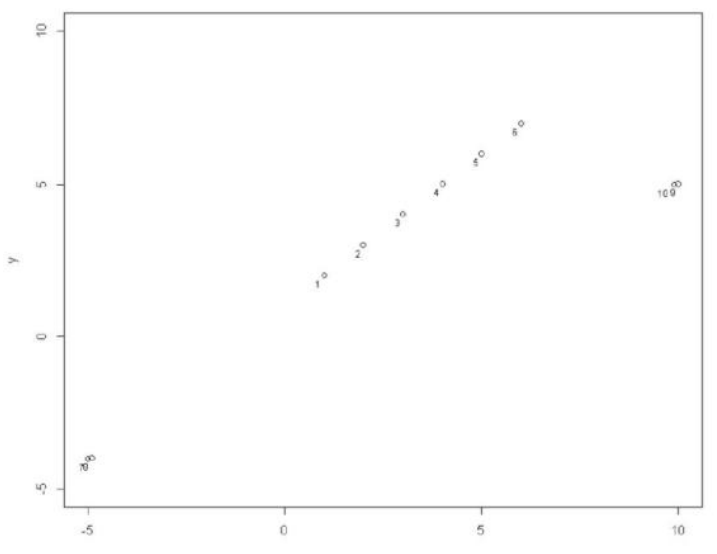

Figure 2.1. Scatter plot of modified Paul-Fung data

Table 2.4. Results of applying Gentleman-Wilk method, Hadi-Simonoff method, reverse Hadi-Simonoff method for Table 2.3 data

\begin{tabular}{clcccc}
\hline 크기 & G-W 이상치 & Hadi-Simonoff 이상치 & 검정 & 역 Hadi-Simonoff 이상치 & 검정 \\
\hline 5 & 348910 & 268910 & $\mathrm{~N}$ & 368910 & $\mathrm{~N}$ \\
4 & 68910 & 68910 & $\mathrm{~N}$ & 68910 & $\mathrm{~N}$ \\
3 & 8910 & 8910 & $\mathrm{Y}$ & 8910 & $\mathrm{Y}$ \\
2 & 910 & 910 & $\mathrm{Y}$ & 910 & $\mathrm{Y}$ \\
1 & 9 & 10 & $\mathrm{~N}$ & 10 & $\mathrm{~N}$ \\
\hline
\end{tabular}

Table 2.5. Artificial data with 2 outliers

\begin{tabular}{lcccccccccc}
\hline ID & 1 & 2 & 3 & 4 & 5 & 6 & 7 & 8 & 9 & 10 \\
\hline$X_{1}$ & 5.3251 & 6.3405 & 9.2053 & 8.9531 & 8.557 & 5.7429 & 5.5882 & 8.8267 & 9.0339 & 7.0505 \\
$X_{2}$ & 1 & 2 & 3 & 4 & 5 & 6 & -5 & -4.9 & 10 & 9.9 \\
$Y$ & 8.1066 & 9.9107 & 13.911 & 14.024 & 17.391 & 13.221 & 1.4282 & 4.6567 & 14.164 & 12.231 \\
\hline
\end{tabular}

로 역 Hadi-Simonoff 방법에서와 동일한 관찰치를 이상치로 탐지하고 있고 세 방법은 모두 관찰치 8이 수렁효과에 영향을 받는 것을 알 수 있다.

예제 2.3: 이상치 탐지과정에서 사용되는 잔차는 일반적으로 전체 모형으로부터 계산되지만 때로는 부 분잔차(partial residual)가 더 유용한 경우가 있다. 부분잔차는 부분선형모형(partial linear model)에 서 비선형 함수의 모양을 식별하는데 사용되며 이 과정에서 이상치를 탐지할 수 있다. 이와 관련된 이상 치 탐지를 위하여 다음과 같이 크기 $n=10$ 의 모의자료를 생성한다 (Table 2.5).

$X_{1}$ 은 $X_{1} \sim 5+5 \times U(0,1)$ 에서 생성되었으며 $X_{2}$ 는 Table 2.3의 $X$ 와 동일하다. $Y$ 는 모형 $Y=$ $X_{1}+Y_{0}+\varepsilon$ 으로부터 생성되었으며 이때 $Y_{0}$ 는 Table 2.3의 $Y$ 와 동일하며 $\varepsilon$ 은 표준정규분포를 따른다. 따라서 모의자료에 대하여 선형모형이나 부분선형모형 $Y=\beta_{1} X_{1}+f\left(X_{2}\right)+\varepsilon$ 을 구현하면 $f\left(X_{2}\right)$ 은 선 형함수로 추정되며 이 과정에서 관찰치 9,10 은 이상치로 탐지되어야 한다.

Table 2.6은 부분선형모형 $Y=\beta_{1} X_{1}+f\left(X_{2}\right)+\varepsilon$ 에서 계산된 부분잔차를 이용하여 이상치를 탐지한 결과를 보여주고 있다. 세 방법 모두 관찰치 5 가 수렁효과에 영향을 받아 이상치를 올바르게 탐지하지 못하는 것을 알 수 있다. 
Table 2.6. Results of applying Gentleman-Wilk method, Hadi-Simonoff method, reverse Hadi-Simonoff method for partial linear model fitted Table 2.5 data

\begin{tabular}{clcccc}
\hline 크기 & $\mathrm{G}-\mathrm{W}$ 이상치 & Hadi-Simonoff 이상치 & 검정 & 역 Hadi-Simonoff 이상치 & 검정 \\
\hline 5 & 145910 & 458910 & $\mathrm{~N}$ & 145910 & $\mathrm{~N}$ \\
4 & 45910 & 45910 & $\mathrm{~N}$ & 45910 & $\mathrm{~N}$ \\
3 & 5910 & 5910 & $\mathrm{Y}$ & 5910 & $\mathrm{Y}$ \\
2 & 910 & 910 & $\mathrm{Y}$ & 510 & $\mathrm{~N}$ \\
1 & 5 & 10 & $\mathrm{~N}$ & 5 & $\mathrm{~N}$ \\
\hline
\end{tabular}

Table 2.7. Artificial data with 5 explanatory variables

\begin{tabular}{ccccccc}
\hline ID & $X_{1}$ & $X_{2}$ & $X_{3}$ & $X_{4}$ & $X_{5}$ & 35.03 \\
\hline 1 & 7.54 & 8.60 & 8.29 & 9.93 & 1.00 & 1.50 \\
2 & 5.65 & 7.21 & 8.17 & 6.78 & 2.00 & 34.11 \\
3 & 9.78 & 8.42 & 5.47 & 9.14 & 2.50 & 34.99 \\
4 & 7.89 & 9.67 & 9.95 & 5.67 & 3.00 & 35.14 \\
5 & 5.50 & 9.76 & 9.09 & 7.70 & 3.50 & 37.69 \\
6 & 9.31 & 8.54 & 9.33 & 7.44 & 4.00 & 33.72 \\
7 & 8.96 & 5.96 & 8.77 & 5.87 & 4.50 & 29.67 \\
8 & 5.16 & 8.86 & 6.15 & 5.48 & 5.00 & 29.87 \\
9 & 6.18 & 7.44 & 6.02 & 5.78 & 5.50 & 37.74 \\
10 & 7.34 & 7.74 & 7.27 & 8.26 & 6.00 & 40.31 \\
11 & 9.25 & 9.79 & 9.57 & 5.98 & -5.00 & 24.96 \\
12 & 6.32 & 9.43 & 8.44 & 5.93 & -4.90 & 26.13 \\
13 & 9.16 & 6.74 & 7.91 & 7.48 & 10.00 & 30.70 \\
14 & 5.12 & 8.72 & 6.84 & 5.89 & 9.90 & 31.43 \\
\hline
\end{tabular}

Table 2.8. Results of applying Gentleman-Wilk method, Hadi-Simonoff method, reverse Hadi-Simonoff method for Table 2.7 data

\begin{tabular}{cllcccc}
\hline 크기 & $\mathrm{G}-\mathrm{W}$ 이상치 & 검정 & Hadi-Simonoff 이상치 & 검정 & 역 Hadi-Simonoff 이상치 & 검정 \\
\hline 5 & 47101415 & $\mathrm{~N}$ & 510121415 & $\mathrm{~N}$ & 47101415 & $\mathrm{~N}$ \\
4 & 7101415 & $\mathrm{~N}$ & 5101415 & $\mathrm{~N}$ & 7101415 & $\mathrm{~N}$ \\
3 & 101415 & $\mathrm{Y}$ & 101415 & $\mathrm{Y}$ & 101415 & $\mathrm{Y}$ \\
2 & 1415 & $\mathrm{~N}$ & 1415 & $\mathrm{Y}$ & 1015 & $\mathrm{~N}$ \\
1 & 10 & $\mathrm{~N}$ & 14 & $\mathrm{~N}$ & 10 & $\mathrm{~N}$ \\
\hline
\end{tabular}

예제 2.4: 설명변수의 개수가 많은 경우 이상치 탐지법을 적용하기 위하여 다음과 같이 5 개의 설명변 수 $X_{1}, X_{2}, X_{3}, X_{4}, X_{5}$ 와 반응변수 $Y$ 를 임의로 생성한다 (Table 2.7). 설명변수 $X_{1}, X_{2}, X_{3}, X_{4}$ 는 $X_{i} \sim 5+5 \times U(0,1) i=1,2,3,4$ 에서 생성되었으며 $X_{5}$ 는 1 에서 6 사이에 동일간격으로 열 한개의 값 을 생성하였고 양극단으로 네 개의 값을 추가하였다. 관찰치 1 에서 13 까지의 반응변수 $Y$ 는 표준정규분 포를 따르는 $\varepsilon$ 을 포함하여 모형 $Y=X_{1}+X_{2}+X_{3}+X_{4}+X_{5}+\varepsilon$ 에서 생성되었으며 관찰치 14 와 15 의 반응변수 $Y$ 는 모형 $Y=X_{1}+X_{2}+X_{3}+X_{4}+X_{5}-6+\varepsilon$ 에서 생성되었다. 따라서 관찰치 14,15 가 이상치로 탐지되어야 한다.

이 자료에 대하여 세 가지 방법을 적용하여 이상치를 탐지한 결과 Table 2.8 에서 보듯이 세 방법은 모두 수렁효과에 영향을 받아 정상치인 관찰치 10 을 이상치로 탐지한다. 
Table 3.1. Clustered Table 2.1 data

\begin{tabular}{ccrr|rrrr}
\hline New ID & Old ID & \multicolumn{1}{c}{$X$} & \multicolumn{1}{c}{$Y$} & New ID & Old ID & $X$ & $Y$ \\
\hline 1 & 243 & 19.90 & 23.900 & 11 & 14 & 9.87 & 10.110 \\
2 & 765 & -4.90 & -8.900 & 12 & 15 & 2.55 & 3.030 \\
3 & 2422 & 4.42 & 4.675 & 13 & 16 & 7.51 & 6.860 \\
4 & 1 & -4.00 & 0.000 & 14 & 17 & 2.67 & 2.100 \\
5 & 8 & 11.36 & 11.100 & 15 & 18 & 4.40 & 3.740 \\
6 & 9 & 11.66 & 11.920 & 16 & 19 & 7.65 & 7.570 \\
7 & 10 & 0.20 & -0.270 & 17 & 20 & 7.01 & 6.400 \\
8 & 11 & 5.27 & 4.950 & 18 & 21 & 1.28 & 1.050 \\
9 & 12 & 10.52 & 11.830 & 19 & 23 & 8.73 & 9.390 \\
10 & 13 & 6.16 & 6.340 & 20 & 25 & 5.47 & 6.040 \\
\hline
\end{tabular}

\section{3. 군집화를 통한 이상치 탐지}

앞 절에서 보듯이 단계별 독립적 이상치 탐지방법이나 순차적 이상치 탐지방법은 모두 가면화 효과나 수렁효과에 취약할 가능성이 있으며 이는 대부분의 경우 인접한 관찰치들을 상반되게 평가하는 경우 에 발생된다. 따라서 관찰치군을 일정기준에 따라 군집화하여 인접한 관찰치들을 동일한 군으로 자료 를 재편성하면 이상치 탐지의 오류를 방지할 수 있다. 군집화는 주로 다변량 자료에서 직접적으로 이 상치군을 탐지할 때 사용되지만 (Atkinson 등, 2004) 군집화를 매개로 모형분석 진단을 수행하는 방법 이 Gray와 Ling (1984) 등에 의하여 시도된 바 있다. Gray와 Ling의 경우에는 영향치군을 탐색함에 있어서 설명변수 행렬 $X$ 뿐만 아니라 반응변수 벡터 $Y$ 가 추가된 행렬을 이용하여 수정된 해트행렬(hat matrix)을 계산하고 수정된 해트행렬이 집단 대각(block-diagonal) 구조를 가지도록 군집화를 통하여 관찰치를 순열화한다. 이와 같은 군집화에 의하여 집단화된 자료에 대하여 영향치 여부를 판단하면 가 면화 효과의 가능성이 낮아지게 된다. 일반적으로 사용되는 이상치의 측도는 잔차등과 같은 단변량 값 이므로 Gray와 Ling의 접근법을 이상치 탐지과정에 직접적으로 적용하는 것은 불가능하지만 관찰치의 위치를 기준으로 자료의 집단화를 수행하면 동일한 효과를 기대할 수 있다.

군집화의 방법은 다양하게 제안되어 있으며 (Cormack, 1971) Gray와 Ling은 인접 이웃 알고리 즘(nearest-neighbor algorithm)을 확장시킨 $k$-군집화 알고리즘( $k$-clustering algorithm)을 사용하 고 있다 (Ling, 1972). 본 논문에서는 자료의 군집화를 위하여 병합적 방법(agglomerative nesting) (Kaufman과 Rousseeuw, 1990)을 사용하며 군집간 연결 기준은 중심연결 방법(centroid linkage method)이고 최종군집을 결정하는 군집간 거리는 0.5 이하로 하고 군집화된 자료의 값은 집단의 평 균값을 사용한다. 군집간 거리에 대한 기준은 cross-validation 등 보다 더 정교한 방법을 적용하는 것도 가능하지만 인위적으로 무리하게 관찰치들이 군으로 분류되지 않도록 작은 값을 적용하였다.

본 연구에서 제안된 방법의 효과를 검증하기 위하여 2 절에서 수행된 예제의 자료를 이용하여 군집화를 통한 이상치군 탐지를 수행한다.

예제 3.1: Table 2.1 자료를 $X, Y$ 에 의하여 군집화 한 결과 8 개의 관찰치가 각각 3 개, 3 개, 2 개씩 모 여 하나의 집단을 형성하게 되어 Table 3.1 과 같은 크기 20 개의 군집화된 자료가 생성된다. 이 자료 를 이용하여 이상치 탐지방법들을 수행하게 되면 Table 3.2 에서 볼 수 있듯이 Gentleman-Wilk 방법과 Hadi-Simonoff 방법, 역 Hadi-Simonoff 방법 모두 군집자료상의 관찰치 $1,2,4$ 를 이상치로 탐지하여 이에 해당하는 원 자료인 Table 2.1 의 관찰치 $1,2,3,4,5,6,7$ 이 이상치로 탐지된다. 
Table 3.2. Results of applying Gentleman-Wilk method, Hadi-Simonoff method, reverse Hadi-Simonoff method for Table 3.1 data

\begin{tabular}{cllllll}
\hline 크기 & G-W 이상치 & Hadi-Simonoff 이상치 & 검정 & 역 Hadi-Simonoff 이상치 & 검정 \\
\hline 7 & 1249121920 & 1249121920 & $\mathrm{~N}$ & 1249121920 & $\mathrm{~N}$ \\
6 & 12491220 & 12491219 & $\mathrm{~N}$ & 12491219 & $\mathrm{~N}$ \\
5 & 124912 & 124920 & $\mathrm{~N}$ & 124920 & $\mathrm{~N}$ \\
4 & 1249 & 1249 & $\mathrm{~N}$ & 1249 & $\mathrm{~N}$ \\
3 & 124 & 124 & $\mathrm{Y}$ & 124 & $\mathrm{Y}$ \\
2 & 14 & 14 & $\mathrm{~N}$ & 14 & $\mathrm{~N}$ \\
1 & 4 & 4 & $\mathrm{Y}$ & 1 & $\mathrm{Y}$ \\
\hline
\end{tabular}

Table 3.3. Clustered Table 2.3 data

\begin{tabular}{cccc|cccc}
\hline New ID & Old ID & $X$ & $Y$ & New ID & Old ID & $X$ & $Y$ \\
\hline 1 & 109 & 9.950 & 5.010 & 5 & 3 & 3.000 & 4.030 \\
2 & 87 & -4.950 & -4.005 & 6 & 4 & 4.000 & 5.030 \\
3 & 1 & 1.000 & 2.010 & 7 & 5 & 5.000 & 6.020 \\
4 & 2 & 2.000 & 3.010 & 8 & 6 & 6.000 & 7.010 \\
\hline
\end{tabular}

Table 3.4. Results of applying Gentleman-Wilk method, Hadi-Simonoff method, reverse Hadi-Simonoff method for Table 3.3 data

\begin{tabular}{cccccc}
\hline 크기 & $\mathrm{G}-\mathrm{W}$ 이상치 & Hadi-Simonoff 이상치 & 검정 & 역 Hadi-Simonoff 이상치 & 검정 \\
\hline 4 & 1234 & 1278 & $\mathrm{~N}$ & 1478 & $\mathrm{~N}$ \\
3 & 178 & 128 & $\mathrm{~N}$ & 128 & $\mathrm{~N}$ \\
2 & 12 & 18 & $\mathrm{~N}$ & 12 & $\mathrm{~N}$ \\
1 & 1 & 1 & $\mathrm{Y}$ & 1 & $\mathrm{Y}$ \\
\hline
\end{tabular}

Table 3.5. Clustered Table 2.5 data by partial residual and $X_{2}$

\begin{tabular}{ccccccccc}
\hline New ID & 1 & 2 & 3 & 4 & 5 & 6 & 7 & 8 \\
\hline Old ID & 87 & 109 & 1 & 2 & 3 & 4 & 5 & 6 \\
$X_{2}$ & -4.950 & 9.950 & 1.000 & 2.000 & 3.000 & 4.000 & 5.000 & 6.000 \\
부분잔차 & -6.946140 & 2.329360 & 0.101392 & 0.835595 & 1.817340 & 2.196070 & 5.980430 & 4.775570
\end{tabular}

예제 3.2: Table 2.3의 수정된 Paul-Fung 자료를 군집화 통해 재정리된 자료는 Table 3.3과 같다. 이 자료에 의해 이상치 탐지법을 적용한 결과 원 자료가 수렁효과에 영향을 받는 것과는 달리 Table 3.4에 서 보듯이 원 자료의 관찰치 9,10 에 해당하는 군집화 자료의 관찰치 1 을 이상치로 올바르게 탐지한다.

예제 3.3: 자료의 군집화는 관련된 변수값을 대상으로 수행할 수 있지만 모형의 추정과정에 따라 군집 대상을 적절히 선택할 수 있다. 부분선형모형에서는 관찰값 $\left(Y, X_{1}, X_{2}\right)$ 을 사용하기 보다는 곡선함수 $f\left(X_{2}\right)$ 를 추정하는데 사용된 부분잔차와 해당 변수 $X_{2}$ 에 의해 군집화를 하는 것이 더 유용하다. Table 3.5 는 $X_{2}$ 와 부분잔차에 의하여 원 자료인 Table 2.5 의 자료를 군집화한 결과를 보여준다.

Table 3.5의 자료를 이용하여 부분잔차와 $X_{2}$ 에 대한 세 가지 추정법을 적용한 결과 Table 3.6 에서 보듯 이 원 자료의 관찰치 9,10 에 해당하는 군집자료의 관찰치 2 가 이상치로 탐지된다.

예제 3.4: 설명변수가 다섯 개인 Table 2.7의 자료를 군집화한 결과는 Table 3.7 과 같다. 군집화된 자 료에 대한 이상치 탐지 결과인 Table 3.8 은 원 자료를 사용한 경우와 달리 원 자료의 관찰치 14,15 에 해 
Table 3.6. Results of applying Gentleman-Wilk method, Hadi-Simonoff method, reverse Hadi-Simonoff method for Table 3.5 data

\begin{tabular}{cccccc}
\hline 크기 & G-W 이상치 & Hadi-Simonoff 이상치 & 검정 & 역 Hadi-Simonoff 이상치 & 검정 \\
\hline 4 & 1267 & 1278 & $\mathrm{~N}$ & 1267 & $\mathrm{~N}$ \\
3 & 126 & 127 & $\mathrm{~N}$ & 267 & $\mathrm{~N}$ \\
2 & 27 & 27 & $\mathrm{~N}$ & 27 & $\mathrm{~N}$ \\
1 & 2 & 2 & $\mathrm{Y}$ & 2 & $\mathrm{Y}$ \\
\hline
\end{tabular}

Table 3.7. Clustered Table 2.7 data

\begin{tabular}{cllcccccc}
\hline New ID & Old ID & $X_{1}$ & $X_{2}$ & $X_{3}$ & $X_{4}$ & $X_{5}$ & \multicolumn{2}{c}{$Y^{29.77}$} \\
\hline 1 & 89 & 5.67 & 8.15 & 6.08 & 5.63 & 4.75 & 31.07 \\
2 & 1415 & 5.28 & 8.60 & 7.00 & 6.03 & 9.95 & 35.03 \\
3 & 1 & 7.54 & 8.60 & 8.29 & 9.93 & 1.00 & 1.50 & 28.76 \\
4 & 2 & 5.65 & 7.21 & 8.17 & 6.78 & 9.14 & 2.00 & 34.11 \\
5 & 3 & 9.78 & 8.42 & 5.47 & 5.67 & 2.50 & 34.99 \\
6 & 4 & 7.89 & 9.67 & 9.95 & 7.70 & 3.00 & 35.14 \\
7 & 5 & 5.50 & 9.76 & 9.09 & 7.44 & 3.50 & 37.69 \\
8 & 6 & 9.31 & 8.54 & 9.33 & 5.87 & 4.00 & 33.72 \\
9 & 7 & 8.96 & 5.96 & 8.77 & 7.27 & 8.26 & 5.50 & 37.74 \\
10 & 10 & 7.34 & 7.74 & 9.79 & 5.98 & 6.00 & 40.31 \\
11 & 11 & 9.25 & 9.79 & 9.57 & 5.93 & -5.00 & 24.96 \\
13 & 12 & 6.32 & 9.43 & 8.44 & 5.48 & -4.90 & 26.13 \\
\hline
\end{tabular}

Table 3.8. Results of applying Gentleman-Wilk method, Hadi-Simonoff method, reverse Hadi-Simonoff method for Table 3.7 data

\begin{tabular}{ccccccc}
\hline 크기 & $\mathrm{G}-\mathrm{W}$ 이상치 & 검정 & Hadi-Simonoff 이상치 & 검정 & 역 Hadi-Simonoff 이상치 & 검정 \\
\hline 4 & 1245 & $\mathrm{~N}$ & 271012 & $\mathrm{~N}$ & 26910 & $\mathrm{~N}$ \\
3 & 2910 & $\mathrm{~N}$ & 2710 & $\mathrm{~N}$ & 2910 & $\mathrm{~N}$ \\
2 & 210 & $\mathrm{~N}$ & 210 & $\mathrm{~N}$ & 210 & $\mathrm{~N}$ \\
1 & 2 & $\mathrm{Y}$ & 2 & $\mathrm{Y}$ & 2 & $\mathrm{Y}$ \\
\hline
\end{tabular}

당하는 군집화 자료의 관찰치 2 가 이상치로 올바르게 탐지되며 군집화는 설명변수가 많은 경우에도 수 렁효과나 가면화 효과의 오류를 개선하는데 효과가 있음을 보여준다.

\section{4. 결론}

본 연구에서는 인접한 관찰치들을 이상치 관점에서 서로 다르게 평가하여 순차적인 이상치 탐지과정에 서 가면화 효과나 수렁효과가 발생하는 것을 개선하고 부수적으로 탐지과정에서 필요한 계산량을 감소 시키는 의도로써 군집화에 의한 이상치군 탐지방법을 제안한다. 군집화의 효과를 검증하기 위하여 적 용된 방법은 Gentleman-Wilk 방법, Hadi-Simonoff 방법, 역 Hadi-Simonoff 방법이다. 그 중에서 역 Hadi-Simonoff 방법은 이상치군의 크기를 줄여가는 순차적 방법인 Hadi-Simoff 방법이 데이터의 크기 가 크면 계산량의 부담이 커진다는 점을 감안하여 가산형 이상치 탐지법으로 제안된 방법이며 절차상 가 면화 효과에 취약할 수 있지만 계산량이 현저히 줄어든다는 장점을 기대할 수 있다. 예제를 통해 세 가 지 방법 모두에서 군집화는 가면화 효과와 수렁효과를 방지하는데 도움이 된다는 것을 검증할 수 있다. 데이터의 크기가 큰 경우 본 논문에서 제안하는 방법은 기초적인 이상치군의 탐색에도 도움이 될 것으로 
기대되며 부분선형모형의 예에서 보듯이 군집화는 관찰치의 위치뿐만 아니라 모형과 환경에 따른 다양 한 값을 기반으로 수행될 수 있다.

\section{References}

Ahn, B. J. and Seo, H. S. (2011). Outlier detection using dynamic plots, The Korean Journal of Applied Statistics, 24, 979-986.

Atkinson, A. C. (1994). Fast very robust methods for the detection of multiple outliers, Journal of the American Statistical Association, 89, 1329-1339.

Atkinson, A. C., Riani, M. and Cerioli, A. (2004). Exploring Multivariate Data with The Forward Search, Springer, New York.

Cormack, R. M. (1971). A review of classification, Journal of the Royal Statistical Society, Series A, 134, 321-367.

Gentleman, J. F. and Wilk, M. B. (1975). Detecting outliers. II . supplementing the direct analysis of residuals, Biometrics, 31, 387-410.

Gray, J. B. and Ling, R. F. (1984). K-clustering as a detection tool for influential subsets in regression, Technometrics, 26, 305-318.

Hadi, A. S. and Simonoff, J. S. (1993). Procedures for the identification of multiple outliers in linear models, Journal of the American Statistical Association, 88, 1264-1272.

Jajo, N. K. (2005). A review of Robust regression an diagnostic procedures in linear regression, Acta Mathematicae Applicatae Sinica, 21, 209-224.

Kaufman, L. and Rousseeuw, P. J. (1990). Finding Groups in Data: An Introduction to Cluster Analysis, Wiley, New York.

Kianifard, F. and Swallow, W. H. (1989). Using recursive residuals, calculated on adaptively-ordered observations, to identify outliers in linear regression, Biometrics, 45, 571-585.

Kianifard, F. and Swallow, W. H. (1990). A Monte Carlo comparison of five procedures for identifying outliers in linear regression, Communications in Statistics, 19, 1913-1938.

Ling, R. F. (1972). On the theory and construction of $k$-clusters, Computer Journal, 15, 326-332.

Marasinghe, M. G. (1985). A multistage procedure for detecting several outliers in linear regression, Technometrics, 27, 395-399.

Paul, S. R. and Fung, K. Y. (1991). A generalized extreme studentized residual multiple-outlier-detection procedure in linear regression, Technometrics, 33, 339-348.

Pena, D. and Yohai, V. J. (1999). A fast procedure for outlier diagnostics in linear regression problems, Journal of the American Statistical Association, 94, 434-445.

Rousseeuw, P. J. (1984). Least median of squares regression, Journal of the American Statistical Association, 79, $871-880$. 